\title{
Heat Generation in the Setting of Magnesium Oxychloride Cements
}

\author{
Edwin S. Newman, John V. Gilfrich, and Lansing S. Wells
}

\begin{abstract}
The heats of hardening of magnesium oxychloride pastes and flooring cements were determined by three methods. Two direct methods limited to 18 hours in duration gave heats of hardening of about $190 \mathrm{cal} / \mathrm{g}$ of $\mathrm{MgO}$. Temperatures up to $147^{\circ} \mathrm{C}$ were obtained in the interior of the samples. A heat-of-solution method, applicable only to the pastes, gave 60-day values for the heat of hardening ranging from 135 to $320 \mathrm{cal} / \mathrm{g}$ of $\mathrm{MgO}$, depending on the relative concentrations of $\mathrm{MgO}, \mathrm{MgCl}_{2}$, and $\mathrm{H}_{2} \mathrm{O}$ in the pastes. A sample stored for 4 years gave a heat of hardening of $240 \mathrm{cal} / \mathrm{g}$ of $\mathrm{MgO}$, as compared with the 60-day value of $215 \mathrm{cal} / \mathrm{g}$ of $\mathrm{MgO}$ for a different sample of similar composition. The low heats of hardening, corresponding to high heats of solution, obtained for certain of the pastes support the conclusion that free $\mathrm{MgO}$ may remain in such pastes.
\end{abstract}

\section{Introduction}

Magnesium oxychloride cement, also called magnesite cement or Sorel cement, is used extensively for floor surfaces. It is formed by the action of concentrated magnesium chloride solution on active magnesium oxide. Numerous filler materials, such as asbestos fiber, hardwood sawdust, talc, sand, and powdered silica, are incorporated to impart desired physical properties to the finished floor. The compound binding these materials together appears to be the magnesium oxychloride $3 \mathrm{MgO} \cdot \mathrm{MgCl}_{2} \cdot 11 \mathrm{H}_{2} \mathrm{O}$ [1]. ${ }^{1}$ This compound is unstable in contact with solutions containing less than 11 percent of $\mathrm{MgCl}_{2}$, and consequently the floor must be protected from the action of water. The conditions of mixing and hardening are such that $\mathrm{MgCl}_{2}$ solution is retained in the interstices of the hardened cement. This solution preserves the oxychloride and renders the floor conductive to electricity, a desirable property in locations where sparks of static electricity may create a hazard.

There appears to be little or no information in the literature on the amount of heat generated by magnesium oxychloride cement while hardening. Chassevent [2] measured the temperature rise during setting of $\mathrm{MgO}-\mathrm{MgCl}_{2}-\mathrm{H}_{2} \mathrm{O}$ mixtures and found that the temperature rises of the pastes and their 7-day compressive strengths increased together. However, he gave no values for the quantity of heat generated. The work reported in this paper had for its primary purpose the determination of the amount of heat generated by several commercial flooring cements. In addition, similar information was obtained concerning mixtures of $\mathrm{MgO}$ and $\mathrm{MgCl}_{2}$ solution without the fillers ordinarily used.

\section{Apparatus and Procedure}

The heat-of-solution method [3] for determining the heat of hardening is not easily applicable to commercial oxychloride cements because of the large proportion and inhomogeneous nature of the filler materials used in their preparation. Consequently,

\footnotetext{
1 Numbers in brackets indicate literature referenes at the end of this paper.
}

direct methods were used to determine the heat of hardening of the commercial cements. In one group of tests, the heat generation was determined by recording automatically the temperatures attained when cement samples enclosed in vacuum flasks were allowed to harden. Detailed descriptions of the apparatus used in these tests have been published $[4,5]$. Weighed samples of the pastes were placed in $1 / 4$-pt friction-top cans provided with thermocouple wells. Three-junction copper-constantan thermopiles were inserted, and the assemblies were placed in widemouthed 1-pt vacuum flasks. The flasks were corked and placed in an air bath maintained at $30.0^{\circ} \mathrm{C}$. The temperatures attained by the pastes during the ensuing $18 \mathrm{hr}$ were recorded.

The vacuum flasks were calibrated electrically. Heaters were built and embedded in plastic in cans identical with those used for the cement samples. The assemblies were placed in the flasks, and the power input was maintained at a constant level until the temperature within the cans became constant. At this point the heat flow from each flask was equal to the power input to that flask. Suitable auxiliary resistances were arranged to enable the current and voltage across the heater coils to be recorded on the same chart as the temperatures. Measurements were made at two levels (besides zero) of power input to the flasks.

The heat-transfer coefficients varied somewhat with temperature because of the large differences in temperature between the interior of the flasks and the surrounding air bath. The total beat lost from a cement sample was evaluated from the time-temperature curve, using the measured values of the heat-transfer coefficient. The sensible heat remaining in the sample, usually a small quantity, was calculated as the product of the final temperature difference and the estimated heat capacity of the sample and container.

A second series of tests were made with a conduction calorimeter similar to that described by Lerch [6]. This apparatus was also calibrated electrically. Because of the more rapid flow of heat from the specimen, the conduction calorimeter permitted the hardening of the cement to occur at lower tempera- 
tures than did the vacuum flasks. The heat of hardening was obtained from the calibration constant and the integration of the time-temperature difference curves. In both these methods the integration was extended over an 18-hr period.

The heats of hardening of oxychloride pastes prepared from $\mathrm{MgO}, \mathrm{MgCl}_{2} \cdot 6 \mathrm{H}_{2} \mathrm{O}$, and water were determined by a modification of the standard method of determining the heat of hydration of portland cement [3]. The heats of solution of $\mathrm{MgO}$ and of the hardened pastes were determined in the vacuumflask calorimeter in $425 \mathrm{~g}$ of $2.00 \mathrm{~N} \mathrm{HCl}$. The heats of dilution of $\mathrm{MgCl}_{2}$ solutions were determined in the same quantity of acid to which $1.0 \mathrm{~g}$ of $\mathrm{MgO}$ had previously been added. The $\mathrm{MgO}$ content of the paste was determined by dissolving a sample in an excess of standard hydrochloric acid and titrating the excess $\mathrm{HCl}$ with $\mathrm{NaOH}$ solution. Methyl red was used as an indicator. In order to prevent the precipitation of $\mathrm{Mg}(\mathrm{OH})_{2}$, approximately $1 \mathrm{~g}$ of solid $\mathrm{NH}_{4} \mathrm{Cl}$ was added to the solution prior to the titration. The $\mathrm{MgCl}_{2}$ content was calculated from the chloride determined by titration with silver nitrate solution, using a second portion of the paste dissolved in nitric acid solution [7]. The $\mathrm{MgO}$ content of the active magnesia used in making the pastes was also determined by titration. The heats of solution were calculated on the basis of the $\mathrm{MgO}$ content. The heats of hardening, also expressed in calories per gram of $\mathrm{MgO}$, were determined by subtracting the heats of solution of the hardened pastes from the heat of solution of the magnesia, corrected for the heat of dilution of the $\mathrm{MgCl}_{2}$ solution contained in the paste.

\section{Materials}

Nine samples of commercial magnesium oxychloride cement were obtained, representing the products of seven manufacturers. These samples were chosen to represent the material made commercially by the larger producers. Magnesium chloride solutions to be used with their product were supplied by the makers, either as solution or as flakes, $\mathrm{MgCl}_{2} \cdot 6 \mathrm{H}_{2} \mathrm{O}$, with directions for preparing solutions of the proper concentration.

TABLE 1. Properties of magnesia samples

\begin{tabular}{|c|c|c|c|c|c|c|}
\hline & \multicolumn{6}{|c|}{ Sample } \\
\hline & 1 & 2 & 3 & 4 & 5 & 6 \\
\hline $\begin{array}{l}\text { Loss at } 110^{\circ} \mathrm{C} \ldots \text { percent } \\
\text { Water in } \mathrm{Mg}(\mathrm{OH})_{2}\end{array}$ & 0.05 & 0.04 & (a) & 0.62 & (a) & 0.12 \\
\hline percent $b_{-}$. & 1.29 & .08 & 4. 13 & 6.02 & 1. 33 & 1.44 \\
\hline Loss on ignition_._. percent _._ & 2.04 & .16 & 6.32 & 8. 43 & 1.73 & 2.42 \\
\hline $\mathrm{CO}_{2} \ldots \ldots$ percent ${ }^{\circ}$ & 0.70 & .04 & 2.19 & 1. 79 & 0.40 & 0.86 \\
\hline Bulk density & .41 & 1. 38 & 0.55 & 0.39 & .79 & .30 \\
\hline $\begin{array}{l}\text { Surface } \\
\text { Hydration in } 24 \mathrm{hr}\end{array}$ & 28.3 & 0.93 & 83.5 & 86.6 & 28.3 & 31.3 \\
\hline Expansion & $\stackrel{80}{0.19}$ & $\begin{array}{l}0 \\
11.0\end{array}$ & $\stackrel{58}{0.09}$ & $\begin{array}{c}77 \\
0.12\end{array}$ & $\stackrel{46}{0.17}$ & $\stackrel{78}{0.26}$ \\
\hline
\end{tabular}

a Gained weight at $110^{\circ} \mathrm{C}$.

b From loss at $450^{\circ} \mathrm{C}$.

c By difference.

d By nitrogen adsorption.

- By ignition loss of 2-g sample mixed with $200 \mathrm{ml}$ of $\mathrm{H}_{2} \mathrm{O}$ and allowed to stand

E B ignition loss of 2-g sample mixed with $200 \mathrm{ml}$ of $\mathrm{H}_{2} \mathrm{O}$ and allowed to stand
' Mixed in the weight ratio 1:19 with portland cement, allowed to harden for $24 \mathrm{hr}$, and autoclaved $3 \mathrm{hr}$ at $300 \mathrm{lb} / \mathrm{in}^{2}$.
Six samples of magnesia used for magnesium oxychloride cement and for other purposes were obtained from a producer. These samples were of differing activities. In table 1 are shown some details of their physical and chemical properties. Magnesium chloride of analytical reagent purity was used to make solutions for use with these magnesia samples.

\section{Results and Discussion}

\subsection{Direct Measurements}

The compositions of the active portions of the nine commercial cements were calculated from the magnesia contents and directions for mixing as given by the manufacturers. Figure 1 shows the compositions of the cement (half-shaded circles) in terms of $\mathrm{MgO}, \mathrm{H}_{2} \mathrm{O}$, and $\mathrm{MgCl}_{2} \cdot 6 \mathrm{H}_{2} \mathrm{O}$. The compounds $5 \mathrm{MgO} \cdot \mathrm{MgCl}_{2} \cdot 12 \mathrm{H}_{2} \mathrm{O}$ and $3 \mathrm{MgO} \cdot \mathrm{MgCl}_{2} \cdot 11 \mathrm{H}_{2} \mathrm{O}$, shown as closed circles, are believed to form in magnesium oxychloride cement. The two compounds $2 \mathrm{MgO} \cdot \mathrm{MgCl}_{2} \cdot 6 \mathrm{H}_{2} \mathrm{O}$ and $9 \mathrm{MgO} \cdot \mathrm{MgCl}_{2} \cdot 14 \mathrm{H}_{2} \mathrm{O}$ [8] are also shown. The composition of the pastes made with the six samples of magnesia, $40 \mathrm{MgO}: 40 \mathrm{MgCl}_{2}$.$6 \mathrm{H}_{2} \mathrm{O}: 20 \mathrm{H}_{2} \mathrm{O}$ by weight, was selected for study after consideration of Chassevent's data [2] in the belief that such pastes would develop the maximum heat of hardening. The composition is very nearly that of the compound $5 \mathrm{MgO} \cdot \mathrm{MgCl}_{2} \cdot 12 \mathrm{H}_{2} \mathrm{O}$, the first to form in the hardening paste $[2,9]$.

The directly measured heats of hardening of the flooring cements (open circles) and of the $\mathrm{MgO}$ $\mathrm{MgCl}_{2}-\mathrm{H}_{2} \mathrm{O}$ pastes (closed circles) are shown in figure 2 and given in table 2. Excluding magnesia sample 3 , which had a very low surface area, the heats of hardening of the pastes and of the flooring

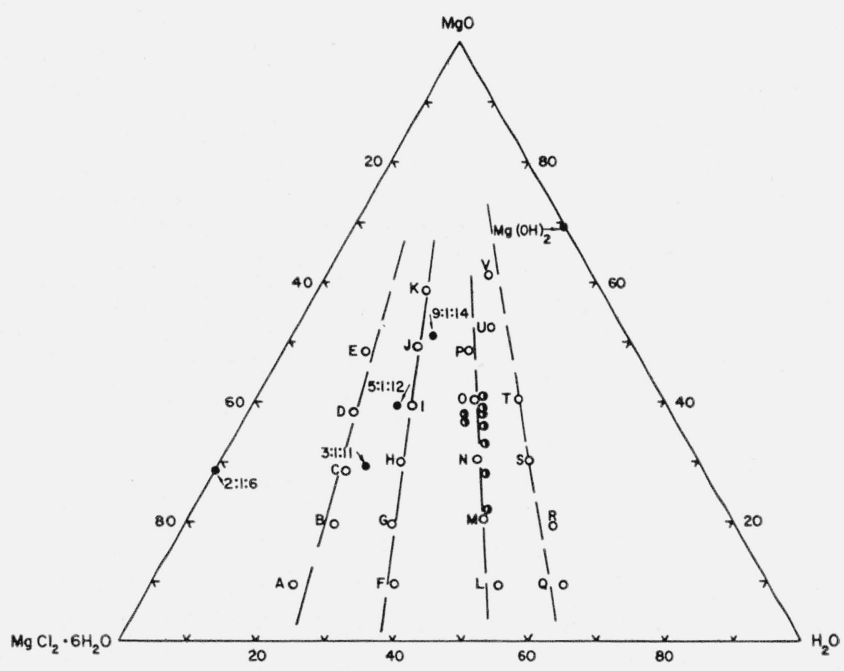

FiguRE 1. Composition of magnesium oxychloride pastes and cements.

, Weight-percent compositions of the pastes prepared for heat-of-solution determinations; composition of the cementitious material in the commercial flooring cements; composition of compounds that have been identified in the flooring cements;
system $\mathrm{MgO}-\mathrm{MgCl}_{2}-\mathrm{H}_{2} \mathrm{O}$. The numbers attached represent the molar proporsystem $\mathrm{MgO}-\mathrm{MgCl}_{2}-\mathrm{H}_{2} \mathrm{O}$. The numbers attached represent the molar propor-
tions of $\mathrm{MgO}, \mathrm{MgCl}_{2}$, and $\mathrm{H}_{2} \mathrm{O}$ that have been assigned to the compounds. tions of $\mathrm{MgO}, \underset{\mathrm{MgCl}}{2}$, and $\mathrm{H}_{2} \mathrm{O}$ that have been assigned to the compoun
Letters near $\mathrm{O}$ identify the samples for easy reference in the text and figure 6 . 
cements were of the same order. Both sets of samples showed a wider range of $18-\mathrm{hr}$ heat of hardening in the vacuum flasks than in the conduction calorimeter. Magnesia samples 1, 5, and 6 all had about the same surface area (table 1 ), and samples 5 and 6 were known to be magnesias used for oxychloride cement. These three each developed $180 \mathrm{cal} / \mathrm{g}$ of $\mathrm{MgO}$ in the vacuum flask compared with an average of 193 $\mathrm{cal} / \mathrm{g}$ of $\mathrm{MgO}$ for the flooring cements, and an average of $203 \mathrm{cal} / \mathrm{g}$ of $\mathrm{MgO}$ in the conduction calorimeter compared with an average of $177 \mathrm{cal} / \mathrm{g}$ of $\mathrm{MgO}$ for the cements. There is some indication, see dotted lines in figure 2 , that the heat generation is greater with smaller percentages of $\mathrm{MgO}$ in the cementitious material. However, as the cements were products of different manufacturers, the magnesias used in their preparation were probably different, and, as the closed circles of figure 2 show, the accidental variation of the heat of hardening among different samples of - oxychloride magnesia could account for this apparent correlation. The two cements showing the higher heats of hardening,

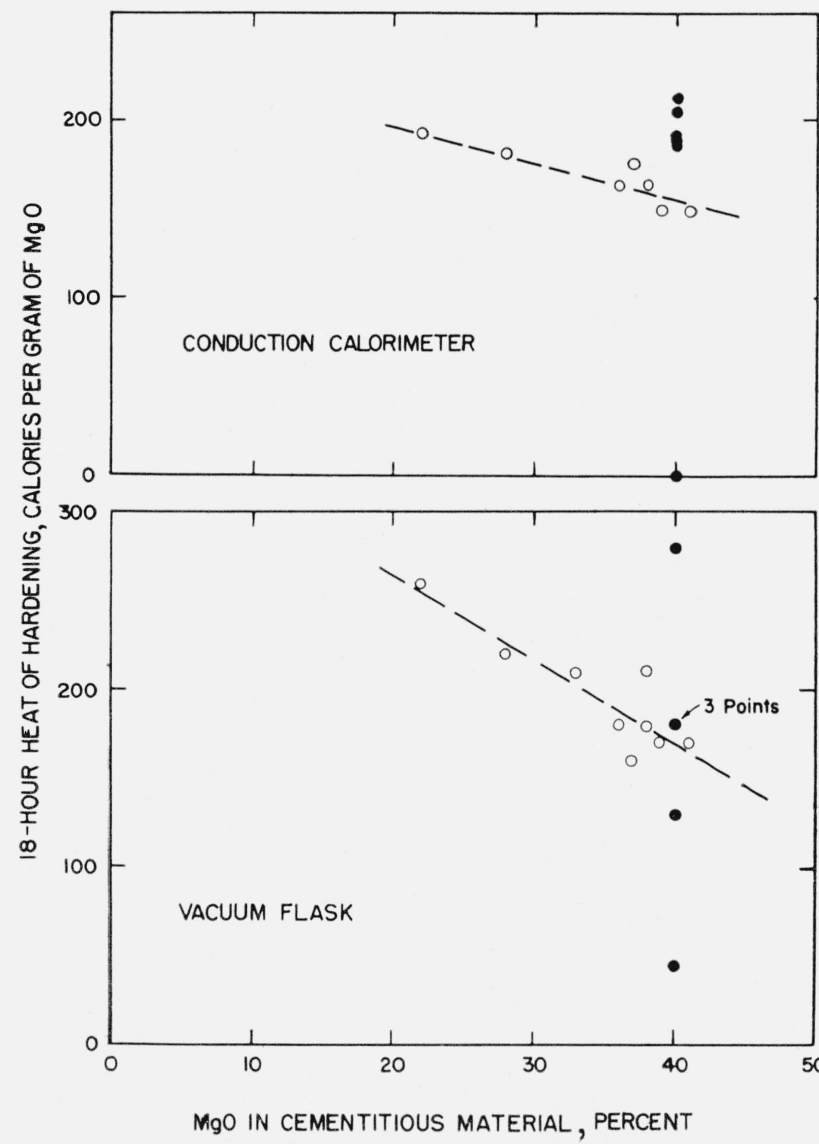

FIGURE 2. Heats of hardening of magnesium oxychloride pastes and cements by direct measurement.

The upper part of the figure represents results obtained in the conduction calorimeter; the lower part, those obtained in a vacuum flask. 0 , Values obtained for commercial flooring cements; , values obtained with $\mathrm{MgO}-\mathrm{MgCl}_{2}-\mathrm{H}_{2} \mathrm{O}$ mixtures commercial flooring cements; , values obtained with $\mathrm{MgO}-\mathrm{MgCl}_{2}-\mathrm{H}_{2} \mathrm{O}$ mixtures
prepared with six different commercially available magnesias. The cements were prepared in the proportions recommended by the manufacturers; the magnesium oxide pastes were all prepared at the same composition, 40 percent of $\mathrm{MgO}, 40$ percent $\mathrm{MgCl}_{2} .6 \mathrm{H}_{2} \mathrm{O}$, and 20 percent $\mathrm{H}_{2} \mathrm{O}$. - - - Change with increasing MgO content of the heat of hardening of the various cements, calculated by the method of least squares. figure 2, are of the same brand. Presumably similar magnesias were used in their preparation. The four points representing these two cements are in excellent agreement with the dotted lines of figure 2. This agreement is to be expected because these are points far enough removed from the rest to be important in giving direction to the curves. Taken by themselves, however, the two cements show a similar trend. This agreement may be taken as additional evidence for the correlation indicated by the dotted lines. The variation of heat of hardening with $\mathrm{MgO}$ content will be demonstrated more fully in the section concerned with heat-of-solution measurements.

TABLE 2. Heats of hardening of magnesium oxychloride cements and pastes

\begin{tabular}{|c|c|c|c|c|c|c|c|c|c|}
\hline \multirow{2}{*}{$\begin{array}{c}\text { Sample } \\
\text { num- } \\
\text { ber }\end{array}$} & \multicolumn{3}{|c|}{$\begin{array}{l}\text { Composition of } \\
\text { cementitious } \\
\text { material }{ }^{a}\end{array}$} & \multicolumn{2}{|c|}{$\begin{array}{c}\text { Heat } \\
\text { generated in } \\
18 \text { hours }\end{array}$} & \multicolumn{2}{|c|}{$\begin{array}{l}\text { Maximum } \\
\text { temperature } \\
\text { reached- }\end{array}$} & \multicolumn{2}{|c|}{$\begin{array}{l}\text { Time to reach } \\
\text { maximum } \\
\text { tempersture }\end{array}$} \\
\hline & $\mathrm{MgO}$ & $\underset{6 \mathrm{H}_{2} \mathrm{O}}{\mathrm{MgCl}_{2}}$ & $\mathrm{H}_{2} \mathrm{O}$ & $\begin{array}{l}\text { Vact- } \\
\text { um } \\
\text { flask }\end{array}$ & $\begin{array}{l}\text { Calo- } \\
\text { rim- } \\
\text { eter }\end{array}$ & $\begin{array}{c}\text { In } \\
\text { vacu- } \\
\text { um } \\
\text { flask }\end{array}$ & $\begin{array}{c}\text { In con- } \\
\text { duc- } \\
\text { tion } \\
\text { calo- } \\
\text { rim- } \\
\text { eter d }\end{array}$ & $\begin{array}{l}\text { Vacu- } \\
\text { um } \\
\text { flask }\end{array}$ & $\begin{array}{l}\text { Con- } \\
\text { duc- } \\
\text { tion } \\
\text { calo- } \\
\text { rim- } \\
\text { eter }\end{array}$ \\
\hline \multicolumn{10}{|c|}{$\mathrm{MgO}-\mathrm{MgCl}_{2}-\mathrm{H}_{2} \mathrm{O}$ mixtures without filler } \\
\hline & $\%$ & $\%$ & $\%$ & $\begin{array}{l}\mathrm{cal} / \mathrm{g} \\
\mathrm{MgO}\end{array}$ & $\begin{array}{l}\mathrm{cal} / \mathrm{g} \\
\mathrm{MgO}\end{array}$ & ${ }^{\circ} \mathrm{C}$ & ${ }^{\circ} \mathrm{C}$ & $h r$ & $h r$ \\
\hline 1 & 40 & 40 & 20 & 130 & 188 & 120 & 54 & $1 / 4$ & 1 \\
\hline 2 & 40 & 40 & 20 & 280 & 178 & 114 & 60 & $3 / 4$ & $11 / 2$ \\
\hline 3 & 40 & 40 & 20 & 44 & (b) & 31 & $\cdots$ & 5 & $-\cdot$ \\
\hline 4 & 40 & 40 & 20 & 180 & 205 & 147 & 38 & $21 / 4$ & $51 / 2$ \\
\hline 5 & 40 & 40 & 20 & 180 & 191 & 132 & 45 & $21 / 2$ & $51 / 2$ \\
\hline 6 & 40 & 40 & 20 & 180 & 213 & 147 & 52 & & $4^{3} / 4$ \\
\hline \multicolumn{10}{|c|}{ Magnesium oxychloride flooring cements } \\
\hline 1 & 38 & 28 & 34 & 180 & 164 & 97 & 29 & $3 \frac{1}{2}$ & $71 / 2$ \\
\hline 2 & 39 & 27 & 34 & 170 & 150 & 87 & 29 & $31 / 2$ & $81 / 2$ \\
\hline 3 & 37 & 31 & 32 & 160 & 176 & 100 & 31 & $31 / 4$ & 8 \\
\hline 4 & 41 & 26 & 33 & 170 & 150 & 97 & 28 & $31 / 2$ & 11 \\
\hline 5 & 38 & 30 & 32 & 210 & $\cdots$ & 77 & -- & $4 \frac{1}{2}$ & --- \\
\hline 6 & 22 & 35 & 43 & 260 & 193 & 70 & 28 & $53 / 4$ & 10 \\
\hline 7 & 28 & 32 & 40 & 220 & 182 & 86 & 28 & $4^{1} / 2$ & 10 \\
\hline 8 & 33 & 30 & 37 & 210 & 149 & 98 & 28 & $41 \frac{1}{4}$ & 10 \\
\hline 9 & 36 & 29 & 35 & 180 & 163 & 96 & 30 & $31 / 4$ & 9 \\
\hline
\end{tabular}

a Calculated in part from information submitted by the manufacturer. Filler material was ignored.

b Not measurable.

c Temperature of surroundings, $30^{\circ} \mathrm{C}$.

d Temperature of surroundings, $25^{\circ} \mathrm{C}$.

It should be pointed out that the conditions of heat flow in the tests made with the vacuum flask approximate the conditions in mass concrete. There has been considerable interest in massive structures made from magnesium oxychloride cement. The conduction calorimeter simulates approximately the conditions in a thin slab of concrete where heat flows readily to the surroundings and excessively high temperatures are not likely to occur. In figure 3 are shown typical time-temperature curves of magnesium oxychloride cement hardening in a vacuum flask. Curve B represents a commercial flooring cement and curve $\mathrm{A}$ the magnesium oxide with which the cement was prepared. Magnesia sample number 5 , tables 1 and 2 , and cement sample number 1 , table 2 , are represented by these curves. 


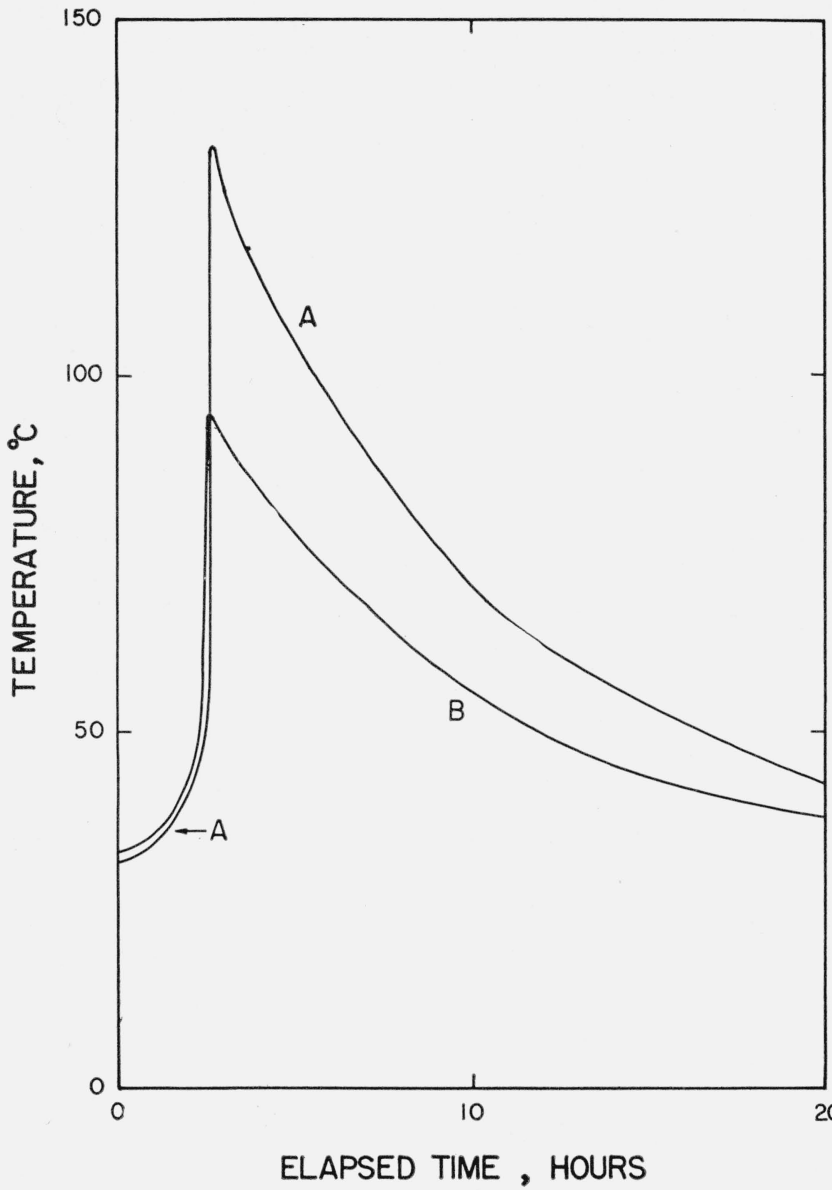

FIGURE 3. Temperature-time relations of a magnesium oxychloride cement and a paste enclosed in a vacuum flask.

Curve B represents the behavior of a commercial flooring cement (sample 1, table 2), and curve A, that of the magnesia (sample 5 , table 2 ) from which it was table 2), and curve A, that of the magnesia (samp
made. Temperature of the surroundings, $30^{\circ} \mathrm{C}$.

Similar curves obtained with the conduction calorimeter are shown in figure 4. The maximum temperature was reached from 3 to $5 \mathrm{hr}$ later in the conduction calorimeter. This delay indicates that the much higher temperatures reached in the vacuum flask accelerate the hardening of the materials.

The compressive strength of magnesite cement is reduced by high temperatures during hardening, such as would occur in the interior of mass concrete. In figure 5 are shown the relative compressive strengths of 2-by 4 -in. cylinders that were allowed to harden for $24 \mathrm{hr}$ enclosed in vacuum flasks. The cylinders were then removed and stored at $25^{\circ} \mathrm{C}$ in the laboratory. Companion specimens were allowed to harden without protection from loss of heat and were similarly stored. The 7-day compressive strengths of the protected specimens, calculated as the percentages of the strengths attained by the unprotected specimens, are plotted against the maximum temperatures reached by the protected specimens. The cements are those listed in table 2, except for sample 4. Reduction in strength occurred for seven out of the eight cements and amounted in one instance to 65 percent. The dotted line in

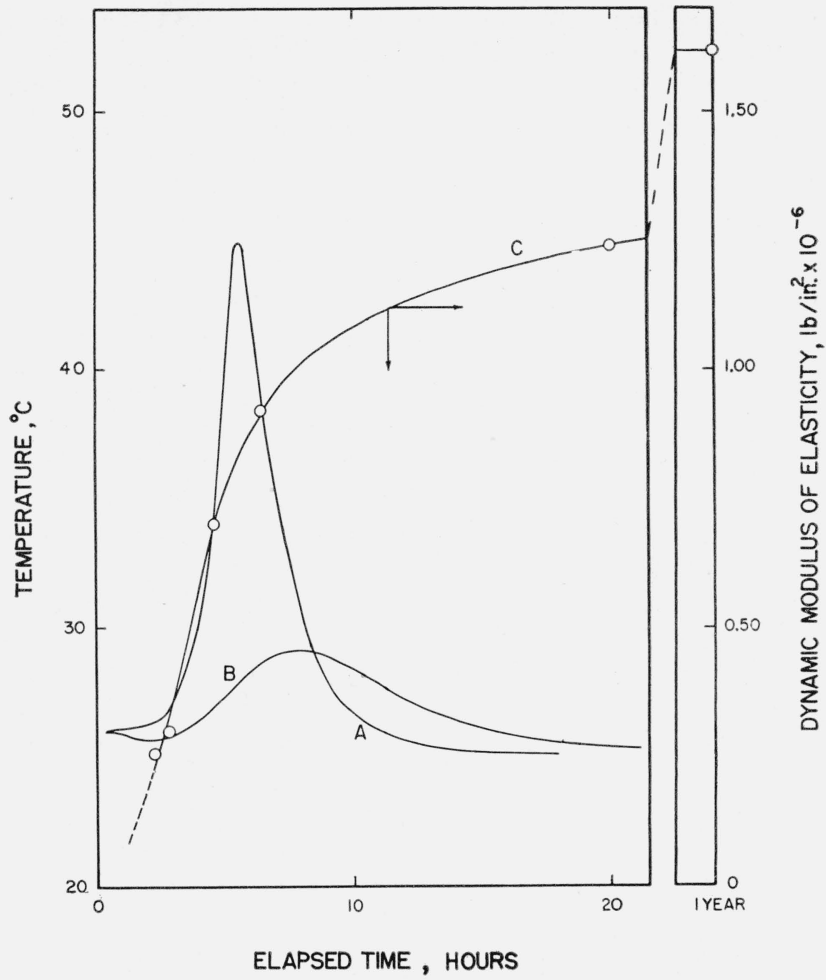

FIGURE 4. Temperature-time relations of a magnesium oxychloride cement and a paste in the Lerch conduction calorimeter, and modulus of elasticity-time relation of the paste:

Curve B represents the behavior of a commercial flooring cement (sample 1 table 2), and curve A, that of the magnesia (sample 5, table 2) from which it was made. Curve $\mathrm{C}$ represents the dynamic modulus of elasticity of a 1 - by 1 . by
$11^{3}$ / 8 -in. bar prepared from paste made with magnesia sample 5 and magnesium chloride solution. Temperature of the surroundings, $25^{\circ} \mathrm{C}$.

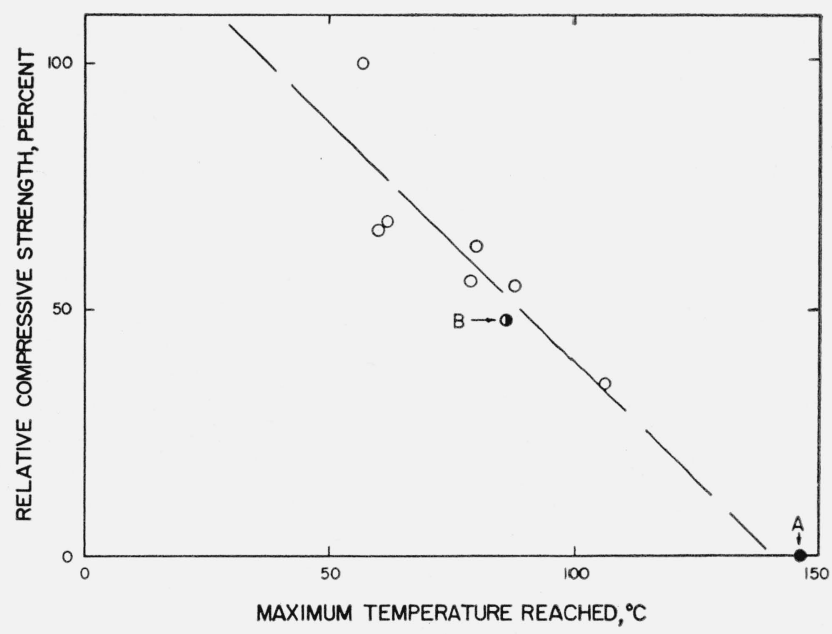

FIGURE 5. Effect of hardening temperature on the compressive strength of magnesium oxychloride flooring cements.

The strengths of 2- by 4-in. cylinders allowed to harden in a vacuum flask, calculated as the percentages of the strength of companion eylinders unprotected against loss of heat, are plotted against the maximum temperature attained in the vacuum flask. Storage conditions: Protected cylinders, 24 hours in vacuum flask, 6 days at $25^{\circ} \mathrm{C}$ and 50 -percent relative humidity; unprotected cylinders, 7 days at $25^{\circ} \mathrm{C}$ and 50-percent relative humidity. The position of the dotted line

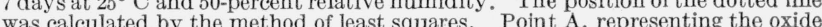
from which cement $\mathrm{B}$ (sample 1, table 2) was made, was omitted from the calcula from which cement B (sample 1, table 2) was made, was omitted from the calcula- 
figure 5 represents the equation calculated from the data by the method of least squares. Point A, which was not included in the calculation, represents magnesia sample 5, and point B represents flooring cement 1 . These are the samples represented by curves $\mathrm{A}$ and $\mathrm{B}$ of figures 3 and 4 . The cylinders represented by point $\mathrm{A}$ disintegrated in 5 days; the 7-day compressive strength, therefore, was plotted as zero.

The sonic method of determining the dynamic modulus of elasticity, $E$, was used to follow the progress of the hardening of 1 - by 1 - by $11^{3 / 3}$-in. bars made of paste prepared with magnesia sample 5, table 1. Curve C, figure 4, shows part of the results of one such series of measurements. The bar hardened sufficiently in $2 \mathrm{hr}$ to be removed from the mold, and measurements were begun at once. The modulus of elasticity at $2.2 \mathrm{hr}$ was $260,000 \mathrm{lb} / \mathrm{in}^{2}$ At $6.4 \mathrm{hr}$ it had increased to $920,000 \mathrm{lb} / \mathrm{in} .{ }^{2}$ and at $20 \mathrm{hr}$ to $1,240,000 \mathrm{lb} / \mathrm{in}^{2}{ }^{2}$, about three-fourths of the value at 1 yr. The most rapid increase in $E$ occurred during the period of rapid increase of heat evolution indicated by curve A of figure 4, although sufficient strength had developed to enable the removal of the specimen from the mold about $2 \mathrm{hr}$ before the rapid evolution became evident. The early and rapid development of a modulus, that is a substantial fraction of the final value, is characteristic of magnesium oxychloride pastes of widely differing compositions.

Insufficient data are available in this work with the commercial cements and active magnesias to separate the effects of temperature of hardening and of variations of the properties of the magnesia. The work does show, however, that the heat of hardening of ordinary magnesium oxychloride pastes and cements is about $190 \mathrm{cal} / \mathrm{g}$ of $\mathrm{MgO}$ (about 50 calories per gram of cement) at $18 \mathrm{hr}$, and that temperatures near the boiling point of water may be reached in the interior of a mass of magnesite cement. This quantity of heat is perhaps five or six times as much as would be developed in the same period in an equal weight of portland cement concrete. Because the oxychloride cement is usually less dense than concrete, from three to four times as much heat would be developed in a given volume of oxychloride cement as in the same volume of concrete.

\subsection{Heat-of-Solution Measurements}

F A systematic study was made of the heats of solution of mixtures of magnesia and magnesium chloride solutions. Magnesium oxide sample 6, table 1, was used with solutions of $\mathrm{MgCl}_{2}$ of analytical reagent purity. The compositions studied are shown as lettered open circles in figure 1 . These points represent the average compositions calculated from the analyses of the paste samples made when the heats of solution were determined. For convenience in reference, samples $\mathrm{A}$ to $\mathrm{E}$ are considered as made with a solution containing 35 percent of $\mathrm{MgCl}_{2}$; samples $\mathrm{F}$ to $\mathrm{K}$, with a 27 -percent solution; $\mathrm{L}$ to $\mathrm{P}$, with a 21 -percent solution ( $22^{\circ}$ Baume); and samples $\mathrm{Q}$ to $\mathrm{V}$, with a 15-percent solution. The last three groups of samples were prepared by adding $\mathrm{MgO}$ to stock solutions of approximately these concentrations, and deviations of the points representing these mixtures from straight lines passing through the $\mathrm{MgO}$ vertex of the diagram (fig. 1) can be due to analytical error only. The first group of samples was prepared by mixing $\mathrm{MgO}$ with the supernatant liquid formed by adding water to a 1-lb bottle of $\mathrm{MgCl}_{2} \cdot 6 \mathrm{H}_{2} \mathrm{O}$ crystals. The concentration of this solution undoubtedly varied from time to time.

The heats of solution of the pastes having compositions indicated by the points in figure 1 were determined at various times after mixing. The heat of solution of the $\mathrm{MgO}$ was also measured. The heats of dilution of the various $\mathrm{MgCl}_{2}$ solutions in 2.00 $N \mathrm{HCl}$ containing $1 \mathrm{~g}$ of added $\mathrm{MgO}$ per $425-\mathrm{g}$ charge of acid were also determined. Duplicate determinations were made using 2- 5- and 10-ml quantities of each of the four solutions. These data were plotted and interpolated values of the heats of dilution appropriate to each heat-of-solution experiment were obtained. The heat of solution of the hardened paste was subtracted from the sum of the heat of solution of the $\mathrm{MgO}$ and the heat of dilution of the magnesium chloride solution. The resulting quantity is the heat of hardening of the paste, and the values so obtained are plotted in figure 6 .

In this figure the pastes in a given column were prepared with solution of the approximate concentration indicated at the top of the column. The columns, therefore, correspond to the lines drawn to the $\mathrm{MgO}$ vertex in figure 1 . All the samples in a given row contained approximately the same percentage of $\mathrm{MgO}$. The rows of figure 6, therefore, correspond approximately to lines drawn in figure 1 parallel to the base and at 10-percent intervals.

The heats of solution are subject to analytical errors from two sources. The first is the inherent error in the determination of the $\mathrm{MgO}$ in the paste sample used for analysis. Judging from the differences between the results for duplicate samples for the same paste, the error in the determination of $\mathrm{MgO}$ was small in most instances. The second source of error was the difficulty in obtaining and transferring certain samples. Paste containing less than 30 percent of $\mathrm{MgO}$ were of such consistency that many could not be weighed accurately and quickly and introduced rapidly into the calorimeter. Consequently, these pastes were exposed to the atmosphere longer than desirable. No entirely satisfactory technique was devised for handling pastes of soapy or greasy consistency. As a result, there was some uncertainty in the weight of the calorimeter sample and in the correspondence of the calorimeter and analytical samples.

It will be seen from figure 6 that the greatest part of the heat of hardening was developed in a short time. Figure 6, N, shows a sample, 30-percent of $\mathrm{MgO}-21$-percent of $\mathrm{MgCl}_{2}$ solution, that at 1 day had developed nearly 80 percent of the 60 -day heat of hardening. Sample $O$ developed nearly 95 percent of the 60-day heat of hardening in 2 days. A sample of approximately the same composition as 


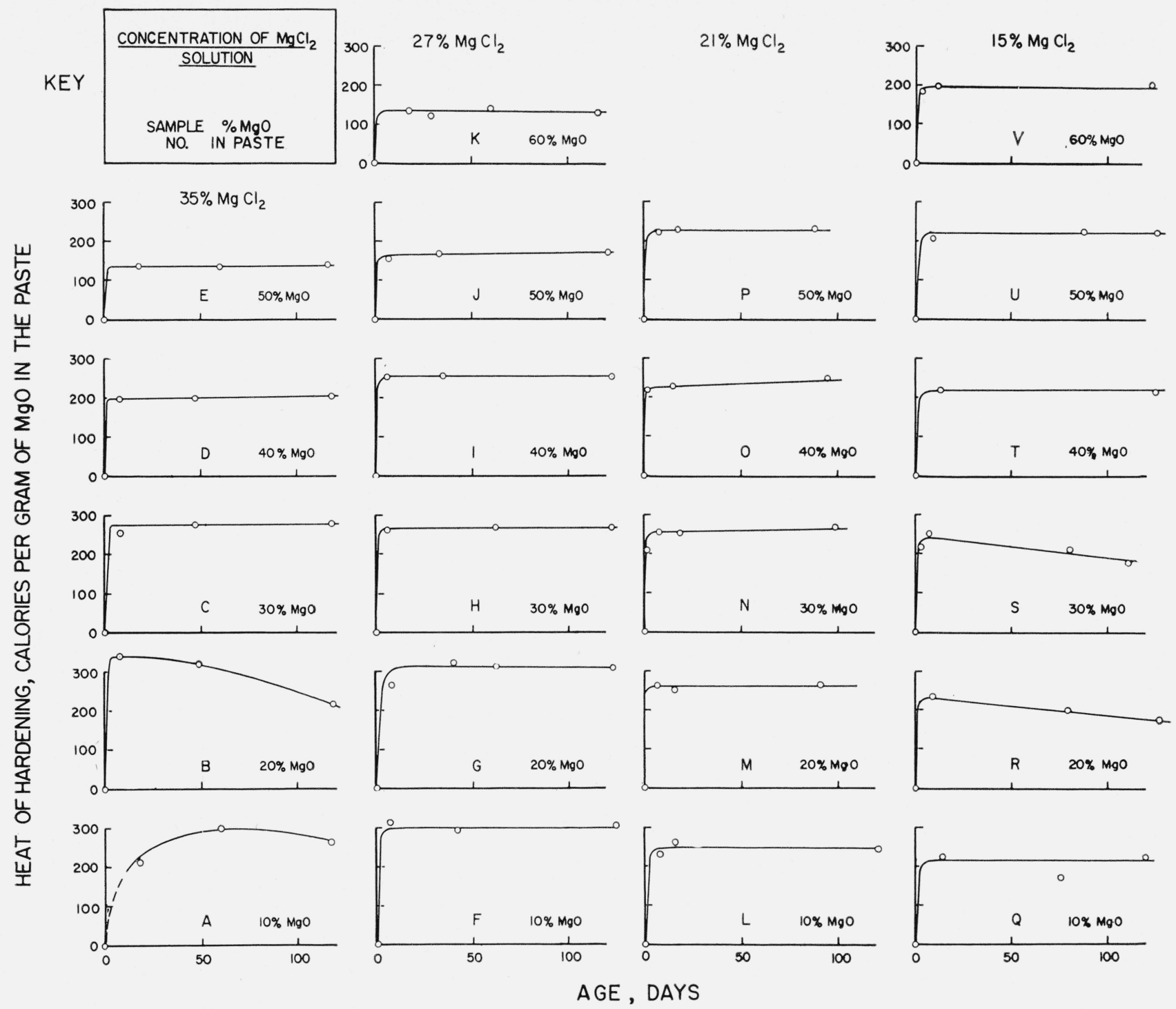

FICURE 6. Heats of hardening of magnesium oxychloride pastes by the heat-of-solution method.

The compositions of the samples, determined by analysis, are indicated by the corresponding letters in figure 1. These pastes were prepared using $\mathrm{MgO}$ No. 6 , table 1 .

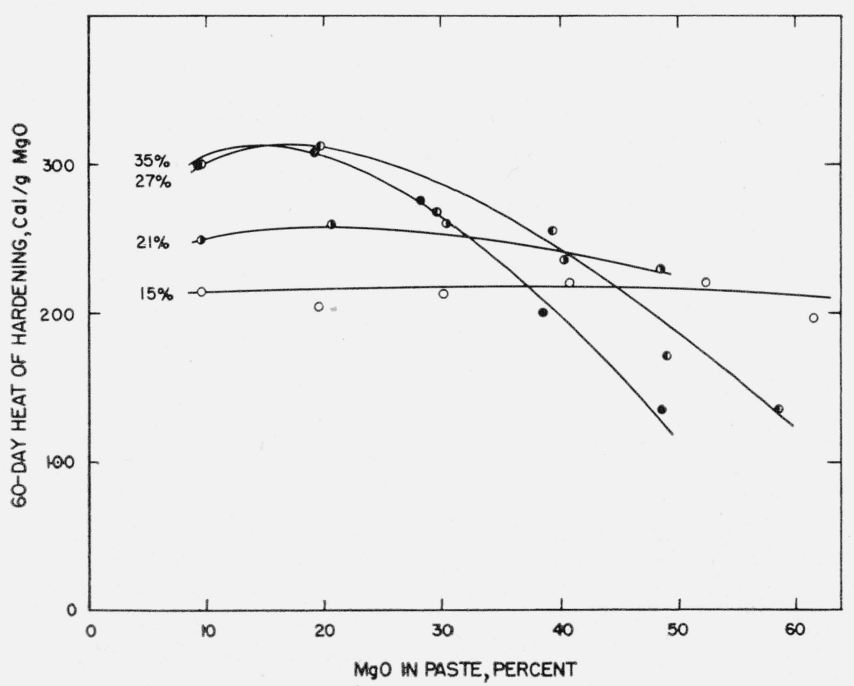

FIGURE 7. Heats of hardenina of magnesium wxychloride pastes.

The 60-day heats of hardening, taken from figure 6, are plotted against the percentage of $\mathrm{MgO}$ in the paste. The percentage figures shown opposite the beginning of each curve give the nominal concentrations of the $\mathrm{MgCl}_{2}$ solutions with ning of each curve give the nom
which the pastes were prepared. 
sample 5 developed $240 \mathrm{cal} / \mathrm{g}$ of $\mathrm{MgO}$ in $4 \mathrm{yr}$. The average 60-day heat of hardening of the samples represented in figure 6 is $225 \mathrm{cal} / \mathrm{g}$ of $\mathrm{MgO}$. These figures and the curves in figure 6 indicate that after the first few days heat generation in magnesium oxychloride cements is very slow. Attention is invited to the curves representing the behavior of samples A, B, R, and S. The values obtained for the heats of solution of these samples indicate that the heat of hardening first increased and then decreased with the elapse of time. The authors can at present offer no convincing explanation of this unexpected behavior, if the apparent trend is real. Although three of these samples were in the composition range where it was difficult to transfer the paste quantitatively because of their consistency, errors in analysis from this cause are not believed to be large enough to cause deviation from the expected trend of the magnitude shown here.

The 60-day heats of hardening from figure 6 are shown in figure 7 , plotted against the percentage of $\mathrm{MgO}$ in the pastes. Here is definite evidence of a change in the heat of hardening of those pastes as a function of the $\mathrm{MgO}$ content. Three of the curves of figure 7 show maxima in the neighborhood of 20 percent of $\mathrm{MgO}$. These curves show that the 60-day heat of hardening of mixtures containing large amounts of $\mathrm{MgO}$ is less than the heat of hydration of $\mathrm{MgO}$ to $\mathrm{Mg}(\mathrm{OH})_{2}, 224 \mathrm{cal} / \mathrm{g}$ of $\mathrm{MgO}$. It has been shown, [9] that unreacted magnesia may remain in magnesium oxychloride pastes after hardening. The pastes studied here were in sealed containers, so that no hydration subsequent to hardening could be caused by moisture from the atmosphere, as apparently occurred in the work cited. X-ray patterns of certain of these pastes also indicated that $\mathrm{MgO}$ was present. The presence of unreacted magnesia in the pastes made with the more concentrated magnesium chloride solutions could account for the low heats of hardening found with the larger amounts of $\mathrm{MgO}$.

The authors acknowledge with gratitude their indebtedness to E. D. West, who made most of the direct measurements, to R. B. Peppler, who devised the analytical methods and made many preliminary heat-of-solution measurements, and to L. P. McGinnis, who prepared many of the pastes and made numerous heat-of-solution determinations.

\section{References}

[1] C. R. Bury and E. R. H. Davies, J. Chem. Soc. (London) p. 2008 (1932).

[2] L. Chassevent, Chimie \& industrie 30, 1020 (1933).

[3] Federal Specification SS-C-158b, May 20, 1946.

[4] P. H. Bates, Proc. Am. Concrete Inst. 25, 88 (1930)

[5] C. H. Jumper and G. L. Kalousek, Rock Products 45, 54 (April 1942).

[6] William Lerch, Am. Soc. Testing Materials Proc. 46 $1252(1 \overline{9} 46)$.

[7] W. C. Pierce and E. L. Haenisch, Quantitative analysis, 2 d ed., p. 247 (John Wiley \& Son, New York, N. Y., 1940).

[8] L. Walter-Levy and Y. Bianco, Compt. rend. 232, 730 (1951).

[9] W. Feitknecht and F. Held, Helv. Chimica Acta 27, 1480 (1944).

Washington, August 1952. 